\title{
El internamiento de extranjeros: un análisis empírico de los procedimientos instruidos en la Comunidad Autónoma Vasca*
}

Iker Barbero

Cristina Blanco

Nieves Arrese

DOI: https://doi.org/10.47623/ivap-rvap.110.2018.1.01

\begin{abstract}
Sumario: I. Introducción.-ll. Regulación del internamiento. -III. Metodología.-IV. Análisis empírico. 1. La detención y la solicitud policial de internamiento. 2. El papel de los operadores jurídicos en la comparecencia. 3. La resolución judicial. 4. Internamiento y modalidades de salida en los CIEs de destino.-V. Conclusiones. - VI. Bibliografía.
\end{abstract}

\section{Introducción}

El internamiento preventivo de extranjeros es una medida cautelar personal propia del actual régimen global de contención de la inmigración (1). Más de 250 campos y centros de detención para inmigrantes se extienden por todo el territorio de la Unión Europea, con una capacidad para más de un millón de personas (Migreurop 2016, Global Detention Project). La reglamentación de la UE prevé que la retención se efectúe, por norma general, en centros de retención especializados, y siempre que se utilicen prisiones las personas extranjeras deben estar separadas de los presos comunes. Sin embargo, en la práctica existe una gran variedad de espacios de retención e internamiento, como las comisarías de policía, los cuarteles militares o los puestos de aduana o zonas de tránsito internacional en puertos y aeropuertos.

* Este artículo es fruto del trabajo llevado a cabo en el seno del Proyecto de investigación de la UPV-EHU, titulado "IUSFUNDIE: Derechos fundamentales y formas actuales de detención, internamiento y expulsión de personas en situación administrativa irregular» (US15/20) www.iusfundie.eu.

(1) WELCH y SCHUSTER (2005); ANDRIJASEVIC (2010). 
En el Estado español, este internamiento se produce en alguno de los ocho Centros de Internamiento de Extranjeros (CIE) diseminados por toda su geografía: Madrid, Barcelona, Valencia, Murcia, Algeciras, Tarifa, Gran Canaria y Tenerife. Si bien las instalaciones de Málaga o Fuerteventura han sido clausuradas por distintos motivos, existe una propuesta gubernamental de abrir tres nuevos centros en Algeciras, Madrid (Aeropuerto de Barajas) y Málaga (2). A esto hay que añadir la reciente experiencia de convertir "temporalmente», y empleando procedimientos legalmente atípicos/irregulares, el centro penitenciario de Archidona (Málaga) en CIE (3). Se trata de emplazamientos «de carácter no penitenciario" en los cuales las personas extrajeras permanecen bajo custodia de la Comisaría General de Extranjería y Fronteras, siendo dirigidos y gestionados por el Cuerpo Nacional de Policía, dependiente del Ministerio del Interior. Sin embargo, pese a tratarse de una cuestión administrativa, está constitucionalmente prohibido que la Administración civil imponga sanciones que, directa o subsidiariamente, impliquen privación de libertad (art. 25.3 CE). La intervención judicial, en teoría, constituye una garantía de los derechos fundamentales de la persona cuando la privación de libertad exceda de setenta y dos horas (art. 17.2 CE). Por lo tanto, como veremos en este artículo, el internamiento de extranjeros se mueve entre el ámbito policial-administrativo y el ámbito judicial penal.

La justificación jurídico-técnica de este sistema de contención administrativa, aplicable exclusivamente a las personas extranjeras (nunca a los nacionales), en tanto que medida cautelar, reside en la necesidad de confinar a la persona mientras se sustancia el expediente sancionatorio por infracción de la Ley de extranjería, o para asegurar la materialización de una orden de expulsión previamente dictada. Según los informes del Mecanismo para la Prevención de la Tortura/Defensor del Pueblo (MPT-DP), en 20156.930 personas extranjeras fueron internadas (6.475 hombres y 455 mujeres). En 2016 esta cifra ha ascendido a 7.597 internamientos ( 7.084 hombres y 513 mujeres). No obstante, en tanto que el objetivo del internamiento es asegurar la expulsión, una de las principales críticas que se esgrimen frente a estos centros es su propia efectividad. En los últimos años, la tasa global de expulsabilidad ronda el $30-40 \%$. De los 6.930 extranjeros internados en 2015, "únicamente»

(2) «El Gobierno quiere tres nuevos Centros de Internamiento de Extranjeros en Algeciras, Madrid y Málaga». Europapress.es, 15 de enero de 2015.

(3) "La cárcel de migrantes de Archidona: una ilegalidad de 1,4 millones de euros. Una semana después de que más de 500 personas migrantes fueran encerradas en una prisión aún sin habilitar, algunos familiares protestan en los alrededores del que ya es un "centro temporal de inmigrantes" para el Gobierno. Abogados Ilevarán el caso ante la Fiscalía y el Tribunal Constitucional por incumplir la Ley de Extranjería». Público.es, 17 de Noviembre de 2017. 
fueron expulsados $2.871(41,43 \%)$; y esta cifra global baja al $30 \%$ en 2016. Esto plantea un cuestionamiento de la efectividad como medida cautelar, en tanto que es relativamente bajo el número de personas que finalmente son expulsadas, más aún cuando se ha sometido a privación de libertad (incluso lejos de su entorno familiar y social) a las que no se ha logrado expulsar. Es lo que ha denominado «deportation turn» (4).

En el País Vasco no hay ubicado ningún $\mathrm{CIE}$, por lo que las personas con orden de internamiento son trasladadas a los centros de Aluche (Madrid), o circunstancialmente al de Zona Franca (Barcelona). El acceso a 211 expedientes de internamiento sustanciados en los juzgados de instrucción del País Vasco durante el 2015, así como a los datos de internamiento de los CIEs de Madrid y Barcelona, nos han provisto de una visión novedosa hasta la fecha(5). Este artículo, basado tanto en el análisis de expedientes judiciales de internamiento como en datos secundarios de internamiento, busca entender algunas de las lógicas que están presentes en estos procedimientos.

Nuestro objetivo ha sido comprobar si, pese a la intervención de un juez del ámbito penal, las garantías formales del proceso son suficientes, especialmente en lo que refiere a la posibilidad de defensa (tiempo para recabar información por parte del abogado, vista/comparecencia relativamente corta y sin grandes posibilidades de medios de prueba) (6); y, al mismo tiempo, comprobar la efectividad del procedimiento en cuanto al cumplimiento de sus objetivos, para lo cual analizamos la relación entre personas detenidas, personas internadas y personas finalmente expulsadas desde los CIEs.

A través del cruce de distintas variables podremos aproximarnos a los principales argumentos esgrimidos por estos actores en momentos como la solicitud policial de internamiento, los argumentos de la defensa letrada y del propio extranjero, los fundamentos judiciales para conceder o denegar el internamiento, o incluso las circunstancias en las que se producen las liberaciones o expulsiones desde los propios CIEs. Esta visión empírica puede ser de gran interés no solo para futuras investigaciones, sino también de gran utilidad para operadores jurídicos como abogados, jueces o fiscales interesados en práctica cotidiana de este procedimiento.

(4) GIBNEY y HANSEN (2003).

(5) BARBERO GONZÁLEZ; BLANCO FERNÁNDEZ DE VALDERRAMA; ARRESE IRIONDO; GONZÁLEZ MURUA (2017). Tal vez, el único estudio similar es el recientemente publicado por GONZÁLEZ BEILFUSS, Markus, sobre el internamiento en la provincia de Barcelona bajo el título "Detention for the purpouse of removal in Spain: Empirical and socio-legal approach to its functioning" en la revista Materiali per una Storia della cultura giuridica, núm. 2, 2017.

(6) RíOS; SANTOS; ALMEIDA (2014). 


\section{Regulación del internamiento}

El internamiento ha estado presente en el ordenamiento jurídico español desde la aprobación de la Ley Orgánica 7/1985, de 1 de julio, sobre derechos y libertades de los extranjeros en España. Esta norma, de manera similar a la actualmente en vigor(7), contemplaba una serie de supuestos, entre los que se incluía "encontrarse ilegalmente en territorio español por no haber obtenido la prórroga de estancia o, en su caso, el permiso de residencia, cuando fueran exigibles", como susceptibles de conllevar la detención del extranjero con carácter preventivo o cautelar mientras se sustancia el expediente sancionador principal. A ese propósito, la autoridad gubernativa que acordara la detención debía dirigirse al juez de instrucción del lugar de la detención, en el plazo de setenta y dos horas, solicitando el internamiento (8). Acordada ésta, su duración máxima no podía exceder de cuarenta días (art. 26 Ley Orgánica 7/1985).

Las reformas de la Ley de Extranjería 4/2000 que de una manera más directa han afectado a la regulación del internamiento de extranjeros han sido las llevadas a cabo por la Ley Orgánica 8/2000, de 22 de diciembre, que introduce una serie de previsiones relativas a las medidas cautelares que cabe adoptar durante la tramitación del expediente sancionador en el que se formule propuesta de expulsión, entre las que se incluye la medida de internamiento (Art. 61 LOEx.) (9). Por su parte, la Ley Orgánica 14/2003, de 20 de noviembre, incluyó en el articulado de la Ley de Extranjería una serie de consideraciones relativas a los derechos de las personas extranjeras internadas, sus deberes, información y reclamaciones, medidas de seguridad y funcionamiento y régimen interior de los centros de internamiento de extranjeros (arts. 62 LOEx). Por otra parte, desaparece de la Ley la mención a la autoridad gubernativa como sujeto habilitado para pedir al juez de instrucción el internamiento de la persona extranjera, que es sustituida por la figura del instructor del procedimiento. Esta Ley también incorpora la referencia a que «el juez, previa audiencia al interesado, resolverá mediante auto motivado, atendidas las circunstancias concurrentes $y$, en especial, el hecho de que carezca de domicilio o de documentación, así como la existencia de condena o sanciones administrativas previas y

(7) Ley Orgánica 4/2000, de 11 de enero, sobre derechos y libertades de los extranjeros en España y su integración social.

(8) La STC 115/1987, de 7 de julio, FJ 1, declaró la constitucionalidad del art. 26.2, párrafo 2. ${ }^{\circ}$, al entender que no era la autoridad administrativa la que privaba de libertad a la persona extranjera, sino la judicial, como se tendrá ocasión de comprobar más adelante.

(9) Esta reforma también implica que el art. 58 hasta ese momento en vigor pase a ser el art. 62. 
de otros procesos penales o procedimientos administrativos sancionadores pendientes" (art. 62.1 LOEx.).

La denominada Directiva de Retorno(10), promulgada en 2008, por su parte, supuso, en términos generales, un endurecimiento de las consecuencias de la situación de irregularidad de las personas extranjeras. En su virtud, cabe internar a aquellas personas extranjeras en situación irregular, en particular, cuando exista riesgo de fuga o se evite o dificulte la preparación del proceso de retorno o expulsión(11), por una duración máxima de seis meses(12), debiendo procederse a su puesta en libertad cuando desaparezcan las citadas condiciones o no exista una perspectiva razonable de expulsión (art. 15).

Finalmente, se ha de mencionar que en 2014 se aprobó el Reglamento relativo a los Centros de Internamiento de Extranjeros(13), siendo su principal función desarrollar las previsiones contenidas en el art. 62 de la Ley Orgánica de Extranjería (14).

Los procedimientos sancionadores que pueden desembocar en la adopción de una sanción de expulsión pueden tramitarse siguiendo el procedimiento ordinario o el preferente(15). En materia de internamiento de personas extranjeras, la opción por la tramitación ordinaria o preferente no es baladí, ya que solo se podrá acordar aquel durante la tramitación del procedimiento preferente(16), no así cuando se siga el

(10) Directiva 2008/115/CE del Parlamento Europeo y del Consejo, de 16 de diciembre de 2008, relativa a normas y procedimientos comunes en los Estados miembros para el retorno de los nacionales de terceros países en situación irregular.

(11) La decisión de internamiento puede ser adoptada por autoridad administrativa o judicial, si bien, en el primer caso, se habrá de establecer un control judicial rápido de legalidad del internamiento o conceder a la persona internada el derecho a incoar un procedimiento para que se someta a control judicial rápido la legalidad de su internamiento.

(12) Se prevé la posibilidad de prorrogar el citado plazo hasta por doce meses más en casos excepcionales, tales como la falta de cooperación o demoras en la obtención de la documentación necesaria.

(13) Real Decreto 162/2014, de 14 de marzo, por el que se aprueba el reglamento de funcionamiento y régimen interior de los centros de internamiento de extranjeros, que sustituyó a la Orden de 22 de febrero de 1999, norma que a la aprobación del RCIE regulaba todo lo relativo a los centros de internamiento de extranjeros. La Sentencia del Tribunal Supremo de 20 de marzo de 2015 anuló alguno de sus preceptos.

(14) LÓPEZ BENÍTEZ (2014); GONZÁLEZ BEILFUSS (2016).

(15) La particularidad de la tramitación preferente es la reducción global de los plazos de cada trámite; así, el plazo de alegaciones se establece en cuarenta y ocho horas (arts. 63.4 LOEx. y 235.1 REx., con advertencia, además, de que si no se efectúan, el acuerdo de iniciación será considerado como propuesta de resolución), el período probatorio en tres días (arts. 63.5 LOEx. y 235.4, párrafo $3 .^{\circ}$ REx.) y el trámite de audiencia en cuarenta y ocho horas (arts. 63.4 LOEx., declarado constitucional por la STC 236/2007, de 7 de noviembre, FJ 16, y 235.4, párrafo $4 .{ }^{\circ}$ REx.).

(16) El art. 63 bis, 3) LOEx., que admite la adopción de medidas cautelares también en el procedimiento ordinario, excluye expresamente el internamiento. 
procedimiento ordinario. Durante la instrucción del procedimiento sancionador, cabe que el órgano instructor solicite motivadamente al juez de instrucción del lugar donde se ha procedido a la detención (art. 62.6 LOEx.) (17) el internamiento de la persona extranjera expulsable (arts. 61.1.d) y 62.1 LOEx.).

La Circular 6/2014, de 11 de julio, de la Dirección General de la Policía-Comisaría General de Extranjería y Fronteras, contiene una serie de circunstancias y criterios que han de ser valoradas por los instructores a la hora de solicitar el internamiento. Éstas se dividen en circunstancias de carácter personal del ciudadano extranjero y circunstancias sobre la posibilidad real de ejecutarse la repatriación. Las primeras, a su vez, pueden ser genéricas (si tiene o no domicilio conocido en España, personas con las que convive y vínculos familiares con los mismos, si tiene hijos menores a su cargo, las consecuencias para él y los miembros de su familia de la expulsión, si tiene arraigo en España, si está provisto de pasaporte, si existe riesgo de fuga o de incomparecencia, si representa un riesgo para el orden público o la seguridad pública o nacional, cualquier otra circunstancia relativa a la existencia de vínculos con España y con su país de origen) y específicas (la edad de la persona implicada, si se trata de persona anciana, si se trata de mujer embarazada, cuál es su estado físico y psíquico, si necesita tratamiento médico o está sujeto a revisiones médicas, si ha padecido algún tipo de violencia física, psíquica, sexual o cualquier tipo de violación o tortura, cualquier otra circunstancia que pueda indicar que se trata de persona vulnerable). En cuanto a las circunstancias sobre la posibilidad real de ejecutarse la repatriación se enumeran las siguientes: si el expedientado está provisto de documento de viaje o pasaporte, si se trata de un nacional de un país que tiene o no representación diplomática o consular en España, si se trata de un nacional que no será documentado por las autoridades consulares de su país, si es nacional de un país que, aunque lo documente, es factible que transcurra el plazo de 60 días máximo del internamiento.

El juez no se ha de limitar a ratificar la solicitud de internamiento presentada por el instructor del procedimiento, sino que adoptará su decisión libremente, atendiendo a las circunstancias concurrentes en cada caso. De ahí que la decisión sobre la pérdida de la libertad sea judicial(18), mien-

(17) La Sentencia del Tribunal Supremo de 20 de diciembre de 2015, dictaminó que la adopción por parte del juez de una medida de internamiento sin previa solicitud del órgano instructor del procedimiento sancionador supone la comisión de un delito de prevaricación imprudente.

(18) La Ley Orgánica de Extranjería prevé la intervención de dos jueces de instrucción: el primero, el del lugar donde se practique la detención de la persona extranjera, será quien autorizará, en su caso, el internamiento. El segundo, el del lugar de internamiento, será el competente para el control de la estancia, art. 62.6 LOEx. 
tras que la expulsión y su ejecución tienen carácter administrativo (19). Y es precisamente esa circunstancia la que determina la constitucionalidad de la medida de internamiento, ya que de esta manera quedan garantizados tanto el derecho a la libertad del art. 17 de la Constitución, como la prohibición de que la administración civil imponga sanciones que impliquen privación de libertad contemplada en el art. 25.3 del texto constitucional.

Por lo que a las posibilidades de impugnar el auto de internamiento se refiere, aunque la normativa sobre extranjería no prevea ningún recurso a estos efectos, por aplicación de la Ley de Enjuiciamiento Criminal cabría la interposición del recurso de reforma, que procede contra todos los autos del juez de instrucción, y cuyo conocimiento corresponde al propio juez de instrucción (arts. 217 y 220 LECr.), y el recurso de queja, ante el tribunal superior competente, que cabe interponerlo contra todos los autos no apelables (arts. 218 y 219 LECr.) (20).

\section{Metodología}

La recogida de información con la que trabajamos en este artículo es doble. Por un lado, hemos realizado el análisis de expedientes de internamiento registrados en los juzgados de instrucción e instrucción y primera instancia en el País Vasco correspondientes al año 2015; por otro lado, y temporalmente posterior, se recibió la respuesta a una solicitud de datos a través de Portal de Transparencia del Gobierno central sobre internamiento en los CIEs de Madrid y Barcelona durante el 2015.

El acceso a los expedientes tramitados fue posible gracias a la colaboración con la Sala de Gobierno del Tribunal Superior de Justicia del País Vasco, los decanatos de cada uno de los partidos judiciales, así como de los y las juezas y letradas de la Administración de Justicia de cada uno de los juzgados. La recogida de datos se realizó con un escrupuloso respeto a las normas de protección de datos sensibles de las personas reflejadas en los expedientes.

(19) STC 115/1987, de 7 de julio, FJ 1. REQUEJO RODRíGUEZ (2006), pág. 107.

(20) No procedería el recurso de apelación, ya que está previsto únicamente para los casos determinados en la ley (art. 217 LECr.) y la Ley Orgánica de Extranjería guarda silencio sobre este particular. 
En total, se han analizado 211 expedientes de internamiento por todo el territorio vasco(21). Entendemos por "expediente de internamiento" el conjunto de documentos jurídicos que componen la carpeta física que es empleada en un procedimiento judicial de internamiento: la solicitud policial (22), el informe fiscal (23), el acta de audiencia (24) y el auto judicial que decreta o deniega el internamiento(25). Para el análisis de todos estos documentos, se ha creado una base de datos especifica(26) que ha permitido recoger información sobre la solicitud policial de internamiento, el perfil del extranjero afectado, la posición del Ministerio Fiscal, la acción de la defensa letrada del extranjero y la resolución del juez de instrucción que ha acabado autorizando (119) o denegando (92) el internamiento.

Respecto a la distribución de la muestra, es preciso señalar que la Comunidad Autónoma del País Vasco se divide, desde el punto de vista judicial, en 14 Partidos Judiciales, en los cuales hay 55 Juzgados de Instrucción Penal o Primera Instancia e Instrucción Penal. En Bizkaia: Balmaseda (1), Barakaldo (4), Bilbao (10), Durango (4), Gernika (4) y Getxo (4); En Gipuzkoa: Azpeitia (2), Eibar (2), Bergara (4), Irún (5), Donostia (5) y Tolosa (4); En Araba: Amurrio (2) y Vitoria-Gasteiz (4). Sin embargo, no todos los partidos judiciales contaban con expedientes de internamiento, tal y como se muestra en la siguiente tabla:

(21) En esta cifra no se incluyen una serie de expedientes que, por distintos motivos, no han podido ser tenidos en cuenta para este estudio. Para el caso de Gipuzkoa, nos fue denegado el acceso por parte del titular del juzgado a un expediente del Juzgado de Instrucción n. ${ }^{\circ} 2$ de Eibar; y en Bergara, uno de los dos expedientes no hacía referencia a un internamiento conocido por ese juzgado sino trasladado a Donostia. En la provincia de Bizkaia, 4 expedientes del Juzgado de Instrucción $n .^{\circ} 5$ de Bilbao se perdieron por un error humano al manipular la aplicación informática. En el caso de Araba, dos expedientes del juzgado número 1 de Vitoria Gasteiz se habían extraviado, uno del juzgado número 3 estaba duplicado en la lista que nos habían facilitado y otro que estaba registrado como internamiento era realmente una requisitoria.

(22) La solicitud policial representa el documento a través del cual el órgano instructor del Cuerpo Nacional de Policía insta el internamiento una vez constatada la existencia de una posible orden de salida obligatoria del país y la necesidad de asegurar la ejecución.

(23) Posición de la Fiscalía respecto a la pertinencia u oposición al internamiento y los argumentos aducidos para una u otra decisión

(24) Acta redactada por el letrado de la Administración de Justicia que describe todas las intervenciones producida en la comparecencia previa a la resolución. En algunos juzgados esta fase se encuentra ya grabada en video y digitalizada en CD.

(25) Pronunciamiento judicial y argumentación en torno a la autorización o denegación del internamiento

(26) Esta base fue diseñada en el marco del proyecto The Social Life of State Deportation Regimes: A Comparative Study of the Implementation Interface (ERC-Starting grant 336319), dirigido por Barak KALIR, de la Universidad de Ámsterdam. 
Tabla 1

Distribución de expedientes por Partido Judicial en el País Vasco (2015)

\begin{tabular}{|c|c|c|}
\hline Partido Judicial & N. ${ }^{\circ}$ & $\%$ \\
\hline Bilbao & 92 & 43,6 \\
\hline Donostia & 50 & 23,7 \\
\hline Vitoria-Gasteiz & 38 & 18,0 \\
\hline Irun & 16 & 7,6 \\
\hline Tolosa & 7 & 3,3 \\
\hline Barakaldo & 4 & 1,9 \\
\hline Gernika & 2 & 0,9 \\
\hline Bergara & 1 & 0,5 \\
\hline Getxo & 1 & 0,5 \\
\hline Eibar, Azpeitia, Durango, Balmaseda y Amurrio & 0 & 0 \\
\hline Total & 211 & 100 \\
\hline
\end{tabular}

Respecto a los datos derivados de la solicitud a través del Portal de transparencia son fruto de la siguiente pregunta: "Tras sendas reuniones mantenidas con los directores de los CIEs de Madrid y Barcelona, y conocer el tipo de registro estadístico que se realiza en estos centros, quisiéramos solicitar la siguiente información ¿Cuántas personas extranjeras han sido internadas en los Centros de Internamiento para Extranjeros de Madrid (Aluche) y Barcelona (Zona Franca) por parte de plantillas del Cuerpo Nacional de Policía ubicadas en el País Vasco? Por años 2010-2016, por sexo, por motivo jurídico, por nacionalidad, por tiempo de internamiento y por resultado (expulsión liberación)». Se trata, por tanto, de datos relativos a la fase posterior, al internamiento. Por cuestiones de unidad y continuidad analizaremos los 132 datos relativos a 2015, o lo que equivale a 110 internamientos en Madrid y 21 en Barcelona. Existe una pequeña desviación numérica entre los datos obtenidos en los juzgados (119 internamientos autorizados) y aquellos aportados por el Ministerio de Interior (135), pero hemos tenido en cuenta ambos datos de manera que no afecte a nuestro análisis ni a las conclusiones (más allá de ser un hecho conclusivo en sí mismo).

\section{Análisis empírico}

\section{La detención y la solicitud policial de internamiento}

La detención de la persona extranjera es la actuación administrativa previa que realiza la policía como medida cautelar dirigida a incoar un expediente sancionatorio o ejecutar una orden de expulsión ya dictada. Du- 
rante el año 2015, 1.913 personas fueron detenidas en la Comunidad Autónoma Vasca (CAV) por infracción de la Ley de Extranjería, según datos proporcionados por la Jefatura Superior de la Policía Nacional. 527 fueron detenidas en la provincia de Bizkaia, 313 en Araba y 1.073 en Gipuzkoa. Debemos indicar que el desequilibrio entre provincias se debe, indudablemente, a la existencia de dos comisarías en Gipuzkoa: una en Donostia-San Sebastián, donde se detuvo a 379, y otra en Irún, con un total de 694 detenciones. Irún no presenta tasas de extranjería significativamente superiores a otros municipios guipuzcoanos, por lo que el factor localidad-frontera interna con Francia parece ser claramente determinante (27). Ahora bien, como veremos más adelante, éste es un factor que apenas tiene incidencia en los casos de internamiento en CIE.

Según el análisis de los expedientes judiciales de internamiento tramitados en 2015, y en lo que refiere al cuerpo policial que realiza la detención, es el Cuerpo Nacional de Policía o Policía Nacional española la que efectúa la gran mayoría de detenciones $(76,3 \%)$, en tanto que tiene encomendada competencialmente la labor de control de fronteras y extranjería (tabla 2). Ahora bien, es posible que en las labores propias de la policía autonómica vasca, Ertzaintza, o de las diferentes policías locales, también se produzcan detenciones de personas extranjeras en situación irregular (un $21.8 \%$ en 2015), que posteriormente son puestas a disposición de la Policía Nacional. En cualquier caso, ésta será siempre la encargada de tramitar el expediente de internamiento.

Tabla 2

\section{Cuerpo policial que realiza la detención}

\begin{tabular}{lcc}
\multicolumn{1}{c}{ Cuerpo policial que detiene } & N. $^{\circ}$ & $\%$ \\
\hline C.N. Policía & 161 & 76,3 \\
Policía Local & 25 & 11,8 \\
Ertzaintza & 21 & 10,0 \\
No consta & 4 & 1,9 \\
\hline Total & $\mathbf{2 1 1}$ & $\mathbf{1 0 0 , 0}$ \\
\hline
\end{tabular}

Fuente: Elaboración propia a partir del análisis de expedientes de internamiento, País Vasco 2015.

Respecto al lugar de detención, hay una clara preferencia a manifestar en los expedientes que la detención se ha producido en la calle (tabla 3).

(27) BARBERO (2017), 1-26. 
Ahora bien, en diversos expedientes la calle a la que se hacía referencia coincidía con las calles donde se ubican las comisarías (Calles Gordóniz de Bilbao o Paseo del Urumea de Donostia-San Sebastián, por ejemplo) o los juzgados (Plaza Teresa de Calcuta, Plaza de Donostia, Ibáñez de Bilbao en Bilbao o en la Avenida Gasteiz de Vitoria-Gasteiz). Esto hace que las comisarías, juzgados o sus proximidades sean otro punto importante en cuanto a lugar de la detención. Es cierto que en un $37 \%$ de los expedientes no consta el lugar de la detención, un elemento que debería incluirse, ya que en determinadas ocasiones podría ser de ayuda a los argumentos de la defensa. Centros de contención como la cárcel o un centro de menores ( 6 detenciones) son también lugares a tener en cuenta, en tanto que la persona está localizada y es previsible su puesta en libertad. Finalmente, es muy llamativo el hecho de que apenas un solo expediente exprese que la persona ha sido detenida en la frontera, cuando la comisaría local de Irún, responsable del control fronterizo, realizó 694 detenciones. Esto puede estar relacionado con el Acuerdo de Readmisión de Extranjeros con Francia (2002), según el cual la readmisión/expulsión se realiza en menos de 72 horas, por lo que no se precisaría de internamiento.

Tabla 3

Lugar de la detención

\begin{tabular}{lccrr} 
& \multirow{2}{*}{ Lugar detención } & Hombres & Mujeres & \multicolumn{2}{c}{ Total } \\
\cline { 4 - 5 } & & & $\mathrm{N}^{\circ}$ & $\%$ \\
\hline Calle & 86 & 6 & 92 & 43,6 \\
No consta & 78 & 1 & 79 & 37,4 \\
Otro & 13 & 2 & 15 & 7,1 \\
Comisaría & 14 & 0 & 14 & 6,6 \\
Salida de prisión & 5 & 0 & 5 & 2,4 \\
Estación de autobuses & 2 & 0 & 2 & 0,9 \\
Bar & 1 & 0 & 1 & 0,5 \\
Centro de acogida de menores & 1 & 0 & 1 & 0,5 \\
Frontera & 1 & 0 & 1 & 0,5 \\
Pensión & 1 & 0 & 1 & 0,5 \\
\hline Total & $\mathbf{2 0 2}$ & $\mathbf{9}$ & $\mathbf{2 1 1}$ & $\mathbf{1 0 0 , 0}$ \\
\hline
\end{tabular}

Fuente: Elaboración propia a partir del análisis de expedientes de internamiento, País Vasco 2015.

Se aprecia una gran concentración de los territorios próximos a las comisarías, ya que la gran mayoría de las detenciones se producen en las capitales de provincia o en Irún, aunque hay algunos municipios disemina- 
dos donde también se detiene, principalmente en Bizkaia y Gipuzkoa. En Araba, todas las detenciones se han producido en la propia ciudad, salvo una que se produjo en Iruña de Oka, ubicación de la cárcel de Langraitz.

Tabla 4

Municipio de detención

\begin{tabular}{lrr}
\hline \multicolumn{1}{r}{ Municipio detención } & N. ${ }^{\circ}$ & $\%$ \\
\hline Bilbao & 54 & 25,6 \\
Donostia / San Sebastián & 49 & 23,2 \\
Vitoria-Gasteiz & 35 & 16,6 \\
Irún & 16 & 7,6 \\
Tolosa & 4 & 1,9 \\
Gernika-Lumo & 2 & 0,9 \\
Hernani & 2 & 0,9 \\
Barakaldo & 1 & 0,5 \\
Bergara & 1 & 0,5 \\
Iruña Oka/Iruña de Oca & 1 & 0,5 \\
Leioa & 1 & 0,5 \\
Mungia & 1 & 0,5 \\
Sopelana & 1 & 0,5 \\
Urnieta & 1 & 0,5 \\
Villabona & 1 & 0,5 \\
No consta & 41 & 19,4 \\
\hline Total & $\mathbf{2 1 1}$ & $\mathbf{1 0 0 , 0}$ \\
\hline
\end{tabular}

Fuente: Elaboración propia a partir del análisis de expedientes de internamiento, País Vasco 2015.

Si miramos la relación entre detenciones por ley de extranjería y comisaría que realiza la solicitud de internamiento en CIE, vemos que hay cierta correlación entre el volumen de detenciones y las solicitudes de internamiento (tabla 5). No obstante, tal y como decíamos anteriormente, siendo Irún la comisaría que más detenciones realiza por motivos de extranjería (694), es Ilamativo que únicamente consten 16 expedientes de internamiento solicitados por la comisaría de Irún (únicamente un 2,3\%). La mayoría de expedientes analizados han sido incoados por la comisaría de Bilbao (99), seguida de Donostia (58), y finalmente Gasteiz (38).

Si nos fijamos en los principales argumentos que emplea la policía para solicitar el internamiento (tabla 6), vemos que "los antecedentes 
policiales" (sin necesariamente sentencia judicial) son un argumento recurrente (en el $88,2 \%$ de los expedientes). No obstante, si reparamos en la naturaleza de tales antecedentes (tabla 7), vemos que el que se cita mayoritariamente es la propia la infracción de la ley de extranjería $(51,7 \%)$ (seguido de delitos contra el patrimonio como hurtos o robos, $40 \%$ ), algo que resulta obvio puesto que el internamiento en CIE sólo se permite para personas en situación irregular (y en muy menor medida personas con expulsión penal). 24 personas carecían de antecedentes policiales y penales, y 115 contaban sólo con antecedentes policiales. Únicamente 71 personas contaban con antecedentes policiales y penales (tabla 8)

Tabla 5

Relación entre detenciones por ley de extranjería y comisaría que realiza la solicitud de internamiento en CIE

\begin{tabular}{lccc}
\hline Comisaría & Detenciones LOEx & Solicitud CIE & $\begin{array}{c}\text { \% solicitudes sobre } \\
\text { total detenciones }\end{array}$ \\
\hline Bilbao & 527 & 99 & 18,8 \\
Donostia & 379 & 58 & 15,3 \\
Irún & 694 & 16 & 2,3 \\
Vitoria-Gasteiz & 313 & 38 & 12,1 \\
\hline
\end{tabular}

Fuente: Elaboración propia a partir del análisis de expedientes de internamiento, País Vasco 2015.

Tabla 6

Argumentos para solicitar el internamiento

\begin{tabular}{lcc}
\hline \multicolumn{1}{c}{ Argumento Policía para Solicitud } & $\mathrm{N} .^{\circ}\left({ }^{*}\right)$ & $\%$ (sobre 211) \\
\hline Antecedentes policiales & 186 & 88,2 \\
Carencia de medios económicos & 168 & 79,6 \\
Carencia de arraigo familiar & 157 & 74,4 \\
Carencia de domicilio estable & 133 & 63,0 \\
Utilización de nombre supuesto & 87 & 41,2 \\
Antecedentes penales & 72 & 34,1 \\
Necesidad de recabar autorización de otros juzgados & 12 & 5,7 \\
Carencia de documentación en trámite & 3 & 1,4 \\
\hline
\end{tabular}

Fuente: Elaboración propia a partir del análisis de expedientes de internamiento, País Vasco 2015.

(*) En cada expediente puede aparecer más de un argumento, por lo que el total de argumentos citados supera al total de expedientes analizados. 
Además de los "antecedentes" (policiales y/o penales), se citan también otros argumentos, como la carencia de medios económicos $(79,6 \%)$, la carencia de arraigo familiar $(74,4 \%)$ y la carencia de domicilio estable (63\%). Es decir, en un porcentaje alto, la policía argumenta que se trata de personas desarraigadas socialmente y sin medios económicos propios para su supervivencia.

Tabla 7

Tipos de antecedentes policiales mencionados en solicitud

\begin{tabular}{lrc}
\hline \multicolumn{1}{c}{ Tipos de antecedentes policiales } & N. ${ }^{\circ}$ & $\%$ \\
\hline Infracción Ley Extranjería & 109 & 51,7 \\
Delito contra el patrimonio & 86 & 40,8 \\
Detención por cuestiones procesales/judiciales & 30 & 14,2 \\
Delito contra las personas & 25 & 11,8 \\
Delito contra agente policial/en detención & 21 & 10,0 \\
Violencia domestica/familiar & 21 & 10,0 \\
Delito contra la salud publica & 11 & 5,2 \\
Falsedad documental & 7 & 3,3 \\
Delito contra la seguridad vial & 3 & 1,4 \\
Asociación ilícita & 1 & 0,5 \\
Delito contra los derechos de los trabajadores & 1 & 0,5 \\
Tenencia armas/municiones/explosivos & 1 & 0,5 \\
\hline Total antecedentes policiales citados & 316 & $\mathbf{1 0 0}$ \\
\hline
\end{tabular}

Fuente: Elaboración propia a partir del análisis de expedientes de internamiento, País Vasco 2015.

Tabla 8

Relación entre antecedentes policiales y antecedentes penales

\begin{tabular}{lccc}
\hline \multirow{2}{*}{$\begin{array}{c}\text { Antecedentes } \\
\text { policiales }\end{array}$} & \multicolumn{2}{c}{ Antecedentes penales } & Total \\
\cline { 2 - 3 } & No & Sí & \\
\hline No & 24 & 1 & 25 \\
Sí & 115 & 71 & 186 \\
\hline Total & $\mathbf{1 3 9}$ & $\mathbf{7 2}$ & $\mathbf{2 1 1}$ \\
\hline
\end{tabular}

Fuente: Elaboración propia a partir del análisis de expedientes de internamiento, País Vasco 2015. 
Teniendo en cuenta que la detención no puede prolongarse más de 72 horas, las solicitudes se efectúan principalmente el mismo día de la detención (117 ó 55,5\%), aunque algunas se prolongan 1 (36\%), $2(6,2 \%)$ o hasta 3 días $(1,4 \%)$.

Tabla 9

Tiempos entre detención y solicitud

\begin{tabular}{lrr}
\hline \multicolumn{1}{c}{ Días } & N. ${ }^{\circ}$ & \multicolumn{1}{c}{$\%$} \\
\hline 0 & 117 & 55,5 \\
1 & 76 & 36,0 \\
2 & 13 & 6,2 \\
3 & 3 & 1,4 \\
Dato erróneo & 2 & 0,9 \\
\hline Total & $\mathbf{2 1 1}$ & $\mathbf{1 0 0 , 0}$ \\
\hline
\end{tabular}

Fuente: Elaboración propia a partir del análisis de expedientes de internamiento, País Vasco 2015.

En lo que refiere al perfil de los detenidos (tablas 10 y 11 ), vemos que se trata mayoritariamente de hombres (202, frente a 9 mujeres) y de edad media (24 a 29 años el $30 \%$, y 30-35 años el 22\%). La principal nacionalidad es la marroquí (74 casos, $35 \%)$, seguida de la argelina $(16 \%)$ y la boliviana en tercer lugar $(4,7 \%)$. Pese a ser unos datos muy bajos, de las 9 mujeres para las que solicitaba internamiento, 3 eran nigerianas y 2 de Liberia.

Tabla 10

Edad de las personas detenidas

\begin{tabular}{lcc}
\hline \multicolumn{1}{c}{ Edad (años) } & N. ${ }^{\circ}$ & $\%$ \\
\hline $18-23$ & 26 & 12,3 \\
$24-29$ & 65 & 30,8 \\
$30-35$ & 47 & 22,3 \\
$36-41$ & 34 & 16,1 \\
$42-47$ & 18 & 8,5 \\
$48-53$ & 17 & 8,1 \\
$54-57$ & 2 & 0,9 \\
No consta & 2 & 0,9 \\
\hline Total & 211 & 100 \\
\hline
\end{tabular}

Fuente: Elaboración propia a partir del análisis de expedientes de internamiento, País Vasco 2015. 
Tabla 11

Nacionalidad de las personas detenidas

\begin{tabular}{|c|c|c|c|c|}
\hline Nacionalidad & Hombre & Mujer & Total & $\%$ \\
\hline Marruecos & 74 & & 74 & 35,1 \\
\hline Argelia & 34 & & 34 & 16,1 \\
\hline Bolivia & 10 & & 10 & 4,7 \\
\hline Pakistán & 8 & & 8 & 3,8 \\
\hline Nigeria & 5 & 3 & 8 & 3,8 \\
\hline Camerún & 6 & & 6 & 2,8 \\
\hline Mongolia & 6 & & 6 & 2,8 \\
\hline Senegal & 6 & & 6 & 2,8 \\
\hline Nicaragua & 5 & & 5 & 2,4 \\
\hline Brasil & 3 & 1 & 4 & 1,9 \\
\hline Ghana & 4 & & 4 & 1,9 \\
\hline Rumania & 4 & & 4 & 1,9 \\
\hline Sierra Leona & 4 & & 4 & 1,9 \\
\hline China & 3 & & 3 & 1,4 \\
\hline Ecuador & 3 & & 3 & 1,4 \\
\hline Paraguay & 2 & 1 & 3 & 1,4 \\
\hline Chad & 2 & & 2 & 0,9 \\
\hline Colombia & 1 & 1 & 2 & 0,9 \\
\hline Georgia & 2 & & 2 & 0,9 \\
\hline Guinea & 1 & 1 & 2 & 0,9 \\
\hline Guinea Bissau & 2 & & 2 & 0,9 \\
\hline India & 2 & & 2 & 0,9 \\
\hline Liberia & & 2 & 2 & 0,9 \\
\hline Venezuela & 2 & & 2 & 0,9 \\
\hline Otros $(*)$ & 13 & 0 & 13 & 6,2 \\
\hline Total & 202 & 9 & 211 & 100,0 \\
\hline
\end{tabular}

Fuente: Elaboración propia a partir del análisis de expedientes de internamiento, País Vasco 2015.

(*) Otros: Un hombre de las siguientes nacionalidades: Burkina Faso, Cabo Verde, Dominica, Guinea Ecuatorial, Honduras, Italia, Kirguistán, Malí, Moldavia, Polonia, Rusia, Sto.Tomás y Príncipe, Túnez.

En relación con el perfil sociodemográfico de las personas que nos ofrecen estos expedientes, puede ser interesante compararlo con el perfil general de personas extranjeras empadronadas en el País Vasco.

Según los datos del INE, el 1 de enero de 2016 había empadronadas en el País Vasco 139.425 personas de nacionalidad extranjera, de las cua- 
les 70.349 eran hombres; esto es, el 50,5\% del total. Sin embargo, de las 211 personas detenidas en el País Vasco durante 2015 y para las que se solicitó ingreso en $\mathrm{CIE}$, el 95,7\% eran hombres. Esto es, hay una clara sobrerrepresentación masculina en los datos de detención en relación con la población general extranjera. Es cierto que las personas detenidas lo son por estancia irregular, mientras que los datos del Padrón (INE) están referidos a residentes empadronados. Pero entre ellos puede haber personas en situación irregular, ya que no se exige autorización legal de residencia para empadronarse en un municipio. Con todo, la diferencia entre unas y otras proporciones es demasiado elevada para deberse simplemente al azar.

Curiosa resulta también la nacionalidad (origen) de las personas detenidas. Si hacemos tres grandes grupos de nacionalidades con las presentes en la tabla 11, y las comparamos con su peso en el conjunto de la población extranjera del País Vasco, podemos ver el gran desequilibrio que hay entre la proporción de esas nacionalidades en el conjunto de personas extranjeras y en el conjunto de personas detenidas (tabla 12 y gráfico 1)

Tabla 12

Proporciones de los diferentes grupos de nacionalidades en el conjunto de la población extranjera y de la población detenida en el País Vasco

\begin{tabular}{lcccc}
\hline \multirow{2}{*}{$\begin{array}{c}\text { Grupos de } \\
\text { nacionalidades (3) }\end{array}$} & \multicolumn{2}{c}{ Población empadronada (1) } & \multicolumn{2}{c}{ Población detenida (2) } \\
\cline { 2 - 5 } & N. ${ }^{\circ}$ & $\%$ & \multicolumn{1}{c}{ N. ${ }^{\circ}$} & $\%$ \\
\hline Magreb & 25.351 & 18,18 & 109 & 51,66 \\
África subsahariana & 12.434 & 8,92 & 36 & 17,06 \\
Latinoamérica & 36.338 & 26,06 & 30 & 14,22 \\
Resto & 65.302 & 46,84 & 36 & 17,06 \\
\hline Total & $\mathbf{1 3 9 . 4 2 5}$ & $\mathbf{1 0 0 , 0 0}$ & $\mathbf{2 1 1}$ & $\mathbf{1 0 0 . 0 0}$
\end{tabular}

Fuentes: (1) INE, Estadística de Padrón Continuo a 1 de enero de 2016; (2) Expedientes de internamiento del País Vasco durante 2015

(3) Grupos en base a las nacionalidades presentes en las detenciones. Magreb: Marruecos, Argelia, Túnez.

África subsahariana: Nigeria, Camerún, Senegal, Ghana, Sierra Leona, Guinea, Guinea Bissau, Guinea Ecuatorial, Cabo Verde, Burkina Fasso, Malí (se excluye a Chad, Liberia y Sto. Tomás, por no estar desagregadas en el Padrón). Latinoamérica: Bolivia, Nicaragua, Brasil, Ecuador, Paraguay, Colombia, Venezuela, Honduras. 
Las personas de nacionalidades magrebíes están muy sobrerrepresentadas en el conjunto de las detenciones, pues suponen el $51,7 \%$ del total de éstas, mientras que sólo constituyen el 18,2\% del total de la población extranjera empadronada en el País Vasco a finales de 2015. Lo mismo ocurre con las subsaharianas $(17 \%$ de los detenidos frente a su proporción general del 8,9\%). Por el contrario, las personas latinoamericanas y del resto de nacionalidades tienen mucho menor peso en las detenciones que entre el conjunto de población extranjera.

\section{Gráfico 1}

Proporciones de los diferentes grupos de nacionalidades en el conjunto de la población extranjera y de la población detenida en el País Vasco (\%)

\section{Empadronados Detenidos}

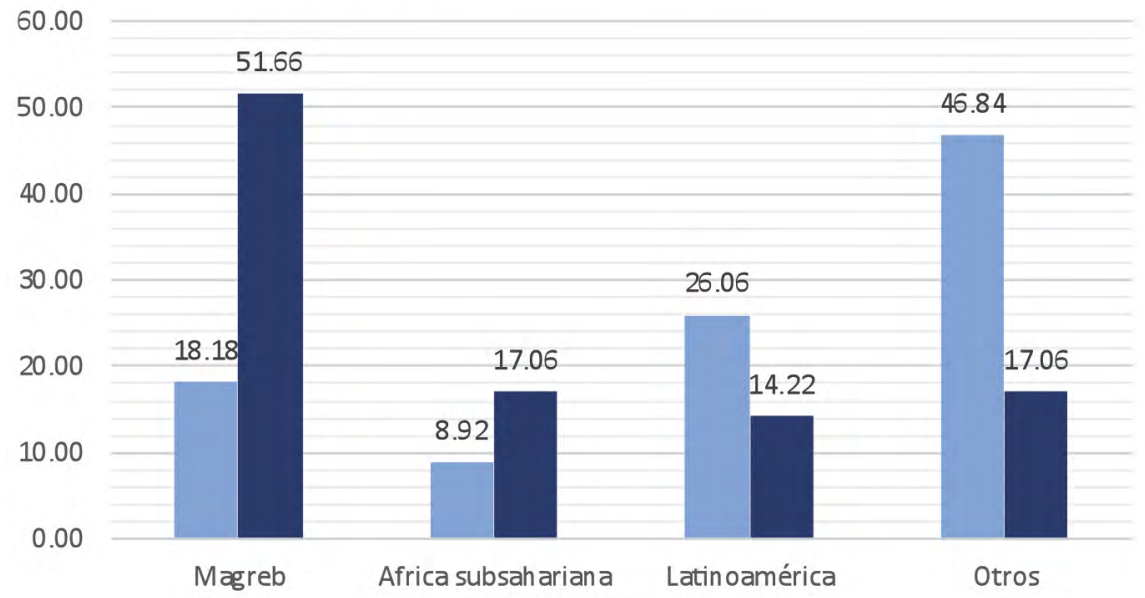

Fuente: Elaboración a partir de los datos de la tabla 12.

En relación a los motivos que justifican la solicitud de internamiento, comprobamos que una gran parte de las órdenes de expulsión se refiere a la mera estancia irregular (81 \%) del 53.1.a) LOEX, siendo esta categoría donde se ubican ocho de las nueve mujeres detenidas (tabla 13). En menor medida (10\%) se produce la «expulsión administrativa por condena penal superior a un año" (57.2 LOEx). Hay otros casos, como la conjunción del 53.1 a) y el 57.2 (7 casos), 5 devoluciones (58.3), 4 expulsiones de ciudadano comunitario (15.c RD 2040/2007) y 2 expulsiones penales (89. CP). 
Tabla 13

Precepto legal que motiva la orden expulsión

\begin{tabular}{lrrrr} 
& & & \multicolumn{2}{c}{ Total } \\
\cline { 4 - 5 } \multicolumn{1}{c}{ Motivo orden expulsión } & Hombres & Mujeres & N. ${ }^{\circ}$ & $\%$ \\
\hline Estancia irregular (53.1 A) & 163 & 8 & 171 & 81,0 \\
$\begin{array}{l}\text { Expulsión administrativa por condena } \\
\text { penal ( 57.2) }\end{array}$ & 21 & 1 & 22 & 10,4 \\
$\begin{array}{l}\text { Estancia irregular (53.1.A) + Expulsión } \\
\text { administrativa por condena penal (57.2) }\end{array}$ & 7 & 0 & 7 & 3,3 \\
$\begin{array}{l}\text { Devolución (58.3) } \\
\text { Expulsión Comunitario (15.c RD }\end{array}$ & 5 & 0 & 5 & 2,4 \\
$\begin{array}{l}\text { 2040/2007) } \\
\text { Sustitución expulsión penal ( 89.CP) }\end{array}$ & 4 & 0 & 4 & 1,9 \\
\hline Total & 2 & 0 & 2 & 0,9 \\
\hline
\end{tabular}

Fuente: Elaboración propia a partir del análisis de expedientes de internamiento, País Vasco 2015.

En general se trata de órdenes de expulsión relativamente coetáneas a las solicitudes (20,4\% son del 2015 y 28,9 del 2014), aunque un $10,4 \%$ (22) se remontan a fechas de 2010 o más antiguas (tabla 14). Es interesante analizar la antigüedad de las órdenes de expulsión en tanto que en aquellos casos de mayor antigüedad podría estudiarse solicitar la revocación puesto que puedan haber aparecido elementos nuevos (arraigo familiar, integración social, etc.) que desaconsejen su expulsión.

Tabla 14

Antigüedad de las órdenes de expulsión

\begin{tabular}{lcr}
\hline \multicolumn{1}{r}{ Año orden expulsión } & N. ${ }^{\circ}$ & \multicolumn{1}{c}{$\%$} \\
\hline 2010 o más antigüedad & 22 & 10,4 \\
2011 & 19 & 9,0 \\
2012 & 27 & 12,8 \\
2013 & 31 & 14,7 \\
2014 & 61 & 28,9 \\
2015 & 43 & 20,4 \\
No consta & 8 & 3,8 \\
\hline Total & $\mathbf{2 1 1}$ & $\mathbf{1 0 0 , 0}$ \\
\hline
\end{tabular}

Fuente: Elaboración propia a partir del análisis de expedientes de internamiento, País Vasco 2015. 
No hay una excesiva dispersión en cuanto a las Subdelegaciones del Gobierno (provinciales) que dictaron la orden de expulsión (tabla 15), ya que un $50 \%$ se dictó en el País Vasco, aunque sí es verdad que la otra mitad hace referencia a provincias alejadas como Madrid (6.2\%), Valencia (4.7\%), Palencia (3.3\%), Ceuta (2.8\%) o Melilla (2,4\%). Para estos casos, debido a la distancia, puede ser más complicado que el abogado que asiste pueda contactar y coordinarse con aquel letrado que asistió originariamente en el expediente de expulsión.

Tabla 15

\section{Subdelegación que decreta expulsión}

\begin{tabular}{lrr}
\hline \multicolumn{1}{c}{ Subdelegación } & N. ${ }^{\circ}$ & $\%$ \\
\hline Gipuzkoa & 38 & 18,0 \\
Araba & 32 & 15,2 \\
Bizkaia & 33 & 15,6 \\
Madrid & 13 & 6,2 \\
Valencia & 10 & 4,7 \\
Palencia & 7 & 3,3 \\
Ceuta & 6 & 2,8 \\
Melilla & 5 & 2,4 \\
Barcelona & 4 & 1,9 \\
Burgos & 4 & 1,9 \\
Córdoba & 4 & 1,9 \\
Navarra & 4 & 1,9 \\
Otras (3 o menos) & 39 & 18,5 \\
No consta & 12 & 5,7 \\
\hline Total & $\mathbf{2 1 1}$ & $\mathbf{1 0 0 , 0}$ \\
\hline
\end{tabular}

Fuente: Elaboración propia a partir del análisis de expedientes de internamiento, País Vasco 2015.

\section{El papel de los operadores jurídicos en la comparecencia}

La comparecencia es el acto procesal en el que la persona extranjera detenida es trasladada a sede judicial para que, asistida de un/a bogado/a, pueda ser interrogada por el fiscal y el juez, así como presentar sus argumentos de defensa por su propia cuenta o ante la pregunta de su abogado. Del análisis de expediente y de la observación de las vistas, podemos decir que éstas no duran más de 10-30 minutos. A la vista de los resultados (tabla 16), casi la mitad de ellas se realizan en el mismo día de 
la detención o al día siguiente (39\%), aunque algunas se dilatan hasta 2 (15) o 3 días (4). Si bien la rápida comparecencia puede evitar que las personas estén en los calabozos innecesariamente o sin la supervisión judicial, también es verdad que el escaso margen de tiempo del que gozan las defensas letradas dificulta en gran medida la recopilación de documentos (documentos que prueben el arraigo o los medios de vida) y argumentos jurídicos para evitar el internamiento.

Tabla 16

Tiempo transcurrido entre la detención y la comparecencia

\begin{tabular}{lrc}
\hline \multicolumn{1}{c}{ Días } & N. & $\%$ \\
\hline 0 & 105 & 49,8 \\
1 & 83 & 39,3 \\
2 & 15 & 7,1 \\
3 & 4 & 1,9 \\
Dato erróneo & 3 & 1,4 \\
No consta & 1 & 0,5 \\
\hline Total & $\mathbf{2 1 1}$ & $\mathbf{1 0 0 , 0}$ \\
\hline
\end{tabular}

Fuente: Elaboración propia a partir del análisis de expedientes de internamiento, País Vasco 2015.

El papel de la Fiscalía, tal y como señala Fernández Olalla, es velar por el cumplimiento de todos los requisitos formales y materiales que son exigibles a una solicitud de internamiento (notificación conforme, caducidad y prescripción, excepcionalidad, proporcionalidad), y que están previstos en la Circular 2/2006 de la FGE de 27 de julio de 2006, sobre diversos aspectos relativos al régimen de los extranjeros en España de en lo referente a la autorización judicial de internamiento administrativo (28). La postura del fiscal queda de manifiesto en dos momentos, en la comparecencia y previamente mediante un informe, si bien la presencia en la comparecencia no es necesariamente física (vía telefónica). Los principales argumentos globales de la Fiscalía para posicionarse favorablemente al internamiento en 147 casos van en consonancia con los ya presentados por la policía, aunque esta institución, en 52 casos, añade argumentos como la falta de arraigo familiar o domicilio estable y, en menor medida, en la carencia de medios económicos o los antecedentes policiales (tabla 17). Por

(28) FERNÁNDEZ OLALLA (2015). 
el contrario, para oponerse al internamiento en 37 casos, señala que la persona tiene domicilio estable $(54,1 \%)$, arraigo familiar $(51,4 \%)$, arraigo social (37,8\%), así como medios económicos suficientes $(29,7 \%)$ (tabla 18$)$.

\section{Tabla 17}

\section{Argumentos de la Fiscalía favorables al internamiento*}

\begin{tabular}{lcc}
\hline \multicolumn{1}{c}{ Argumentos para justificar internamiento } & $\begin{array}{c}\text { N. }{ }^{\circ} \text { de veces } \\
\text { empleado }\end{array}$ & $\%$ \\
\hline Carencia de arraigo familiar & 13 & 25,0 \\
Carencia de domicilio estable & 11 & 21,2 \\
Carencia de medios económicos & 6 & 11,5 \\
Antecedentes policiales & 2 & 3,8 \\
Utilización de nombre supuesto & 1 & 1,9 \\
Antecedentes penales & 1 & 1,9 \\
Necesidad de recabar autorización de otros juzgados & 0 & 0,0 \\
Carencia de documentación en trámite & 0 & 0,0 \\
Otros & 18 & 34,6 \\
\hline Total de veces empleados & $\mathbf{5 2}$ & $\mathbf{1 0 0} \%$ \\
\hline
\end{tabular}

Fuente: Elaboración propia a partir del análisis de expedientes de internamiento, País Vasco 2015.

(*) Argumentos que la Fiscalía añade a los ya presentados en la solicitud policial.

Tabla 18

Argumentos de la Fiscalía para oponerse al internamiento

\begin{tabular}{lcc}
\hline \multicolumn{1}{c}{ Argumentos para oponerse al internamiento } & $\begin{array}{c}\text { N. }{ }^{\circ} \text { de veces } \\
\text { empleado }\end{array}$ & $\%$ \\
\hline Domicilio estable & 20 & 54,1 \\
Arraigo familiar & 19 & 51,4 \\
Arraigo social & 14 & 37,8 \\
Medios económicos suficientes & 11 & 29,7 \\
Notificación defectuosa & 2 & 5,4 \\
Orden expulsión no firme & 2 & 5,4 \\
Salud & 1 & 2,7 \\
\hline Total de veces empleados & $\mathbf{6 9}$ & $\mathbf{1 0 0 \%}$ \\
\hline
\end{tabular}

Fuente: Elaboración propia a partir del análisis de expedientes de internamiento, País Vasco 2015. 
En la personación ante el juez, la persona extranjera tiene derecho a la asistencia letrada que, en su caso, se le proporcionará de oficio (art. 235.2 REx.) (29), quedando así garantizados los derechos fundamentales de defensa (30).

En lo que a los argumentos para la defensa se refiere, hemos considerado tanto lo pronunciado por el abogado como por la propia persona detenida en las respuestas a las preguntas de juez y fiscal o a iniciativa propia. En este sentido ambas coinciden en poner el énfasis en el arraigo familiar $(42,7 \%$ y $46 \%$, respectivamente), seguido del domicilio estable (42,7\% ambos) así como los medios económicos suficientes y el arraigo social, en torno éstos al $30 \%$. En algunos casos se ha hecho referencia la notificación defectuosa de la orden de expulsión o su desconocimiento (10-15\%) o su no firmeza y posibilidad de recurso (9,5\% de los argumentos de los letrados), y en muy menor medida la inconsistencia de los antecedentes policiales (en torno al $2 \%$ ) o cuestiones de salud (2-3\%).

\section{Tabla 19}

\section{Argumentos para la defensa}

\begin{tabular}{lcccc}
\hline \multirow{2}{*}{\multicolumn{1}{c}{ Argumentos defensa }} & \multicolumn{2}{c}{ Extranjero/a } & \multicolumn{2}{c}{ Abogado/a } \\
\cline { 2 - 5 } & $\mathrm{N} .^{\circ}$ & $\%$ & $\mathrm{~N} .{ }^{\circ}$ & $\%$ \\
\hline Arraigo familiar & 97 & 46,0 & 90 & 42,7 \\
Domicilio estable & 90 & 42,7 & 90 & 42,7 \\
Medios económicos suficientes & 64 & 30,3 & 54 & 25,6 \\
Arraigo social & 59 & 28,0 & 65 & 30,8 \\
Otros & 51 & 24,2 & 91 & 43,1 \\
Notificación defectuosa & 33 & 15,6 & 22 & 10,4 \\
Orden expulsión no firme & 6 & 2,8 & 20 & 9,5 \\
Antecedentes policiales insuficientes & 4 & 1,9 & 6 & 2,8 \\
Salud & 4 & 1,9 & 7 & 3,3 \\
Tiene autorización residencia & 3 & 1,4 & 4 & 1,9 \\
\hline
\end{tabular}

Fuente: Elaboración propia a partir del análisis de expedientes de internamiento, País Vasco 2015.

(29) SOLANES CORELLA (2016), págs. 60-61.

(30) STC 115/1987, de 7 de julio, FJ 1. Sobre la conveniencia de que el abogado que asista a la persona internada sea el mismo que interviene en el procedimiento de expulsión, véase TOMÉ GARCÍA (2014), págs. 179-183. 


\section{La resolución judicial}

El juez adoptará su decisión conforme al procedimiento de diligencias previas previsto en la Ley de Enjuiciamiento Criminal (arts. 774-779) (31). Así, el internamiento se acordará previa audiencia de la persona interesada (32) y del Ministerio Fiscal (33), mediante auto motivado (34). El juez decidirá sobre la petición de internamiento de acuerdo con el principio de proporcionalidad, atendiendo a todas las circunstancias concurrentes $y$, en especial, al riesgo de incomparecencia por carecer de domicilio o de documentación identificativa, a las actuaciones de la persona extranjera tendentes a dificultar o evitar la expulsión, a la existencia de condenas o sanciones administrativas previas y de otros procesos penales o procedimientos sancionadores pendientes (art. 62.1 LOEx.) (35). Por su parte, si la persona extranjera padeciera una enfermedad grave, el juez valorará el riesgo del internamiento para la salud pública o para su propia salud (36). Lo expuesto, pone de manifiesto que la medida de internamiento ha de ser excepcional, "de modo que no es la sustanciación del expediente de expulsión, sino las propias circunstancias del caso, por razones de seguridad, orden público, etc., las que han de justificar el mantenimiento de esa pérdida de libertad» (37).

Prácticamente la mitad de las solicitudes (119) han sido resueltas favorablemente al internamiento, bajo el argumento judicial principal de la falta de arraigo (argumentada en el $74,8 \%$ de los casos de autorización), la carencia de domicilio $(73,9 \%)$ o la carencia de medios económicos de vida $(70,6 \%)$ (tabla 21$)$. Es decir, mientras que la policía hacía una lectura de la necesidad de internamiento en clave de peligrosidad, los jueces y juezas de instrucción se centran en el desarraigo social y económico de la persona. La otra cara de la moneda es que estos mismos argumentos sir-

(31) Así lo indicó la STC 115/1987, de 7 de julio.

(32) Aspecto contemplado en el art. 6.6 de la Directiva de Retorno.

(33) Exigencia introducida por la Ley Orgánica 2/2009. Sobre la función garantista que compete al Ministerio Fiscal en este tipo de procedimientos sancionadores, véase SOLANES CORELLA (2016), pág. 59.

(34) La no motivación del auto de internamiento es susceptible de recurso de amparo ante el Tribunal Constitucional, STC 169/2008, de 15 de diciembre, FJ 4. Se ha puesto de relevancia la importancia de que además del principio periculum in mora, también se atienda al principio fumus boni iura, tal y como contempla la STJUE de 30 de noviembre de 2009, C-357/09, Said Shamilovich Kadzoev (Huchbarov). SÁNCHEZ TOMÁS (2015), págs. 71-72.

(35) La no motivación del auto de internamiento o la motivación genérica, cuando el auto se refiera a un colectivo sin relación entre ellos, es considerada como vulneradora de los derechos fundamentales de la persona extranjera. SSTC 144/1990, de 26 de septiembre, FFJJ 4 y 5; 96/1995, de 19 de junio, FJ 2; 182/1996, de 12 de noviembre, FJ 3. Véase ADAM MUÑOZ (1991), págs. 970-971.

(36) Esta previsión, además de algunas otras precisiones, han sido introducidas por la LO 2/2009.

(37) STC 115/1987, de 7 de julio, FJ 1. 
ven para 92 resoluciones de denegación del internamiento $(60 \%$ arraigo familiar; $59,8 \%$ domicilio estable; $40,2 \%$ arraigo social...) (tabla 22 ).

Tabla 20

\section{Sentido de la resolución}

\begin{tabular}{cccc} 
& Autoriza & Deniega & Total \\
\hline $\mathrm{N} .{ }^{\circ}$ & 119 & 92 & 211 \\
$\%$ & 56,4 & 43,6 & 100,0 \\
\hline
\end{tabular}

Fuente: Elaboración propia a partir del análisis de expedientes de internamiento, País Vasco 2015.

Tabla 21

Argumentos judiciales para autorizar el internamiento ( $N=119$ )

\begin{tabular}{lcc}
\multicolumn{1}{c}{ Argumentos para autorizar } & N. & $\%$ \\
\hline Falta de arraigo & 89 & 74,8 \\
Carencia domicilio & 88 & 73,9 \\
Carencia de medios de vida & 84 & 70,6 \\
Antecedentes policiales & 38 & 31,9 \\
Antecedentes penales & 23 & 19,3 \\
Nombre & 18 & 15,1 \\
Documentación & 3 & 2,5 \\
Autorizaciones & 2 & 1,7 \\
Otros & 60 & 50,4 \\
\hline
\end{tabular}

Fuente: Elaboración propia a partir del análisis de expedientes de internamiento, País Vasco 2015.

Tabla 22

\section{Argumentos judiciales para denegar el internamiento ( $N=92)$}

\begin{tabular}{lrr}
\hline \multicolumn{1}{c}{ Argumentos para denegar } & N. & $\%$ \\
\hline Arraigo familiar & 56 & 60,9 \\
Domicilio estable & 55 & 59,8 \\
Arraigo social & 37 & 40,2 \\
Medios económicos suficientes & 28 & 30,4 \\
Orden expulsión no firme & 9 & 9,8 \\
No notificación & 8 & 8,7 \\
Antecedentes policiales insuficientes & 6 & 6,5 \\
No obstaculiza a la expulsión & 4 & 4,3 \\
Salud & 4 & 4,3 \\
Tiene autorización residencia & 1 & 1,1 \\
Otros & 51 & 55,4 \\
\hline
\end{tabular}

Fuente: Elaboración propia a partir del análisis de expedientes de internamiento, País Vasco 2015. 
Ya nos hemos referido a los tiempos que van entre la detención y la comparecencia para decidir el internamiento, pero ahora debemos fijarnos en el tiempo que transcurre entre la comparecencia y la resolución. Prácticamente el total de las resoluciones se toman el mismo día, es decir, salvo en casos de comparecencias de última hora del día, los y las magistradas toman las decisiones de manera inmediata (tabla 23)

Tabla 23

Tiempo transcurrido entre la comparecencia y la resolución

\begin{tabular}{lrr}
\hline \multicolumn{1}{c}{ Días } & $\mathrm{N}^{\circ}{ }^{\circ}$ & \multicolumn{1}{c}{$\%$} \\
\hline 0 & 204 & 96,7 \\
2 & 1 & 0,5 \\
Dato erróneo & 4 & 1,9 \\
No consta & 2 & 0,9 \\
\hline Total general & $\mathbf{2 1 1}$ & $\mathbf{1 0 0 , 0}$ \\
\hline
\end{tabular}

Fuente: Elaboración propia a partir del análisis de expedientes de internamiento, País Vasco 2015.

Si bien es difícil hablar de tasas de autorización o denegación por juzgados, debido al bajo número de asuntos tramitados en la mayoría de estos órganos, sí podemos hacer algún breve comentario sobre los que mayor volumen han tenido. Por ejemplo, el Juzgado n. ${ }^{\circ} 1$ de Gasteiz, órgano que más solicitudes ha conocido (16), autorizó en un 87,5\% de las ocasiones; o el n. 9 de Bilbao que, con 13 solicitudes, se acerca a la media, con un $53,8 \%$ de denegaciones (7); o el n. 2 de Donostia que, de las 13 solicitudes que se le presentaron, únicamente autorizó 2 (15\%). Los juzgados 5-6-10 de Bilbao, con 10 casos, rondan el 70 y $80 \%$ de autorizaciones. Algunos juzgados presentan un $100 \%$ de autorizaciones o denegaciones, pero eso puede ser debido al bajo número de solicitudes que se le plantean, como el juzgado $n .{ }^{\circ} 3$ de Irún que autorizó las 5 solicitudes (tabla 24). 
Tabla 24

Cómputo de resoluciones por órgano y sentido de la resolución

\begin{tabular}{|c|c|c|c|c|c|}
\hline \multirow{2}{*}{ Órgano judicial } & \multicolumn{2}{|c|}{ Autoriza } & \multicolumn{2}{|c|}{ Deniega } & \multirow{2}{*}{ Total } \\
\hline & $\mathrm{N} .^{\circ}$ & $\%$ & N. ${ }^{\circ}$ & $\%$ & \\
\hline Total $\mathbf{n} .^{\circ}$ & 119 & 56,4 & 92 & 43,6 & 211 \\
\hline Gasteiz 1 & 14 & 87,5 & 2 & 12,5 & 16 \\
\hline Bilbao 9 & 6 & 46,2 & 7 & 53,8 & 13 \\
\hline Donostia 2 & 2 & 15,4 & 11 & 84,6 & 13 \\
\hline Donostia 5 & 7 & 58,3 & 5 & 41,7 & 12 \\
\hline Bilbao 3 & 5 & 45,5 & 6 & 54,5 & 11 \\
\hline Bilbao 4 & 4 & 36,4 & 7 & 63,6 & 11 \\
\hline Bilbao 10 & 7 & 70,0 & 3 & 30,0 & 10 \\
\hline Bilbao 5 & 8 & 80,0 & 2 & 20,0 & 10 \\
\hline Bilbao 6 & 8 & 80,0 & 2 & 20,0 & 10 \\
\hline Donostia 3 & 5 & 50,0 & 5 & 50,0 & 10 \\
\hline Bilbao 1 & 2 & 25,0 & 6 & 75,0 & 8 \\
\hline Bilbao 8 & 7 & 87,5 & 1 & 12,5 & 8 \\
\hline Donostia 4 & 3 & 37,5 & 5 & 62,5 & 8 \\
\hline Gasteiz 2 & 4 & 50,0 & 4 & 50,0 & 8 \\
\hline Gasteiz 3 & 3 & 37,5 & 5 & 62,5 & 8 \\
\hline Donostia 1 & 6 & 85,7 & 1 & 14,3 & 7 \\
\hline Bilbao 7 & 1 & 16,7 & 5 & 83,3 & 6 \\
\hline Gasteiz 4 & 3 & 50,0 & 3 & 50,0 & 6 \\
\hline Irun 3 & 5 & 100,0 & 0 & 0,0 & 5 \\
\hline Bilbao 2 & 2 & 50,0 & 2 & 50,0 & 4 \\
\hline Irun 1 & 2 & 66,7 & 1 & 33,3 & 3 \\
\hline Irun 2 & 2 & 66,7 & 1 & 33,3 & 3 \\
\hline Irun 5 & 2 & 66,7 & 1 & 33,3 & 3 \\
\hline Tolosa 4 & 2 & 66,7 & 1 & 33,3 & 3 \\
\hline Barakaldo 3 & 2 & 100,0 & 0 & 0,0 & 2 \\
\hline Gernika 4 & 1 & 50,0 & 1 & 50,0 & 2 \\
\hline Barakaldo 2 & 0 & 0,0 & 2 & 100,0 & 2 \\
\hline Irun 4 & 2 & 100,0 & 0 & 0,0 & 2 \\
\hline Tolosa 2 & 1 & 50,0 & 1 & 50,0 & 2 \\
\hline Bergara 1 & 1 & 100,0 & 0 & 0,0 & 1 \\
\hline Bilbao 6 & 1 & 100,0 & 0 & 0,0 & 1 \\
\hline Getxo 6 & 0 & 0,0 & 1 & 100,0 & 1 \\
\hline Tolosa 1 & 0 & 0,0 & 1 & 100,0 & 1 \\
\hline Tolosa 3 & 1 & 100,0 & 0 & 0,0 & 1 \\
\hline
\end{tabular}

Fuente: Elaboración propia a partir del análisis de expedientes de internamiento, País Vasco 2015. 
Por otra parte, resulta interesante fijarse en la correlación entre la posición del fiscal y la del magistrado. En 110 ocasiones ambas instituciones judiciales han mantenido la misma postura: decretar el internamiento. Sin embargo, hay ocasiones en las que el juez se ha apartado de la línea propuesta por la Fiscalía, pero esto solo ocurre para denegar el internamiento (37 ocasiones). Más Ilamativo resulta que en el 100\% de las veces que la Fiscalía era contraria al internamiento, el juez o jueza de instrucción ha mantenido el mismo criterio de no internamiento (tabla 25).

Tabla 25

Relación entre Fiscalía y Juez/a

\begin{tabular}{lccc}
\hline \multirow{2}{*}{ Posición Fiscal } & \multicolumn{2}{c}{ Posición Juez } & \multirow{2}{*}{ Total } \\
\cline { 2 - 4 } & Autoriza & Deniega & 27 \\
\hline No sabemos* & 9 & 18 & 147 \\
No se opone & 110 & 37 & 37 \\
Se opone & 0 & 37 & $\mathbf{2 1 1}$ \\
\hline Total & $\mathbf{1 1 9}$ & $\mathbf{9 2}$ & \\
\hline
\end{tabular}

Fuente: Elaboración propia a partir del análisis de expedientes de internamiento, País Vasco 2015.

(*) Casos en los que no hay información debido a que ésta se encuentra en un CD al que no se ha tenido acceso

Llegados a este punto, puede ser interesante preguntarse en qué medida hay similitudes o diferencias entre los datos de internamientos del País Vasco y los del conjunto del Estado, en relación a la detención de extranjeros por infracción de la ley de extranjería. La tabla 26 nos ofrece una diferencia importante de casi 12-13 puntos porcentuales: en Euskadi se interna bastante menos que en el total del Estado; o dicho de otra manera, la tasa de detención es muy alta considerando la posterior tasa de autorización del internamiento. Una vez más, debemos ser conscientes de que un número importante de las detenciones de la comisaría de Irún lo son para ejecutar readmisiones automáticas a Francia (sin pasar por juzgado ni $\mathrm{CIE}$ ). Si elimináramos la variable fronteriza, quitando las detenciones de la comisaría de Irún (siendo conscientes de que no todas son en frontera), el porcentaje de internamiento subiría al $10-11 \%$. 
Tabla 26

\section{Comparativa Euskadi-Estado de la tasa de internamiento en relación a las detenciones por extranjería}

\begin{tabular}{lccc}
\hline & Detenidos & Internados & \% internamiento \\
\hline Estado español (1) & 36.327 & 6.930 & 19,1 \\
Euskadi IUSFUNDIE (2) & 1.913 & 119 & 6,2 \\
Euskadi Transparencia (3) & 1.913 & 131 & 6,8
\end{tabular}

Fuentes: Elaboración propia a partir de datos del Mecanismo para la Prevención de la TorturaDefensoría del Pueblo (1), del análisis de expedientes de internamiento en el País Vasco durante 2015 (2) y datos del Portal de Transparencia (Ministerio del Interior) (3).

\section{Internamiento y modalidades de salida en los CIEs de destino}

El País Vasco se encuentra dentro de la demarcación administrativa territorial noroeste de la península, a la que le corresponde el CIE de Aluche (Madrid). Así, la regla general es que se solicite (y decrete) el internamiento en ese centro (179 personas). No obstante, algunas nacionalidades, como la argelina, se destinan al CIE de la Zona Franca de Barcelona debido a que el consulado argelino designado a la zona norte para el reconocimiento previo de sus nacionales es el de Barcelona, mientras que el de Madrid se encargaría de los nacionales de Argelia internados desde de la zona sur de España. También es cierto que, en ocasiones en las que no es necesario el reconocimiento o no hubiera plazas en el CIE de Zona Franca, los argelinos pueden ser internados en Aluche.

Tabla 27

CIE de ingreso

\begin{tabular}{|c|c|}
\hline $\mathrm{CIE}$ que se solicita & Total \\
\hline Madrid & 179 \\
\hline Barcelona & 28 \\
\hline No Consta & 4 \\
\hline Total general & 211 \\
\hline
\end{tabular}

Fuente: Elaboración propia a partir del análisis de expedientes de internamiento, País Vasco 2015.

Resulta interesante ver que los tiempos de internamiento rondan los 30 días de media en Madrid y 19 en Barcelona, aunque la franja de mayor frecuencia se sitúa entre los 0-7 días $(29 \%)$ y los 8-15 días $(22,1 \%)$. 
Tabla 28

Tiempos de estancia en CIE (en días)

\begin{tabular}{lrr}
\hline \multicolumn{1}{r}{ N. $^{\circ}$ días } & N. & \multicolumn{1}{c}{$\%$} \\
\hline $0-7$ & 38 & 29,0 \\
$8-15$ & 29 & 22,1 \\
$16-22$ & 17 & 13,0 \\
$23-30$ & 13 & 9,9 \\
$31-37$ & 6 & 4,6 \\
$38-45$ & 8 & 6,1 \\
$46-52$ & 8 & 6,1 \\
$53-60$ & 12 & 9,2 \\
\hline Total & 131 & 100,0 \\
\hline
\end{tabular}

Fuente: Ministerio del Interior a través del Portal de Transparencia

Aplicando un análisis de cruce de variables, para ver si se produce alguna correlación entre ellas, podemos percibir una tendencia curiosa entre la variable "tiempo" y la variable "expulsión»: a medida que avanza el tiempo, disminuye la probabilidad de ser finalmente expulsado. Mientras que en la primera semana la probabilidad de expulsión es del 78,95\%, va cayendo hasta el $42,8 \%$ en la cuarta, un $33 \%$ en la sexta y un $17 \%$ a partir de las 7 semanas. Se aprecia un breve pico en el medio, entre la cuarta y quinta semana (tabla 29 y gráfico 2 ).

Tabla 29

Probabilidad de expulsión según criterio temporal

\begin{tabular}{lrrrr}
\hline \multirow{2}{*}{ Semanas internamiento } & Total & \multicolumn{2}{c}{ Expulsión } & \\
\cline { 3 - 4 } & & No & Sí & \\
\hline hasta 1 & 38 & 8 & 30 & 78,9 \\
de 1 a 2 & 24 & 6 & 18 & 75,0 \\
de 2 a 3 & 20 & 6 & 14 & 70,0 \\
de 3 a 4 & 14 & 8 & 6 & 42,9 \\
de 4 a 5 & 6 & 2 & 4 & 66,7 \\
de 5 a 6 & 6 & 3 & 3 & 50,0 \\
de 6 a 7 & 6 & 4 & 2 & 33,3 \\
más de 7 semanas & 17 & 14 & 3 & 17,6 \\
\hline Total general & $\mathbf{1 3 1}$ & $\mathbf{5 1}$ & $\mathbf{8 0}$ & $\mathbf{6 1 , 1}$ \\
\hline
\end{tabular}

Fuente: Ministerio del Interior a través del Portal de Transparencia 


\section{Grafico 2}

Proporciones de expulsiones según tiempo transcurrido en $\mathrm{CIE}$, en semanas $(\%)$

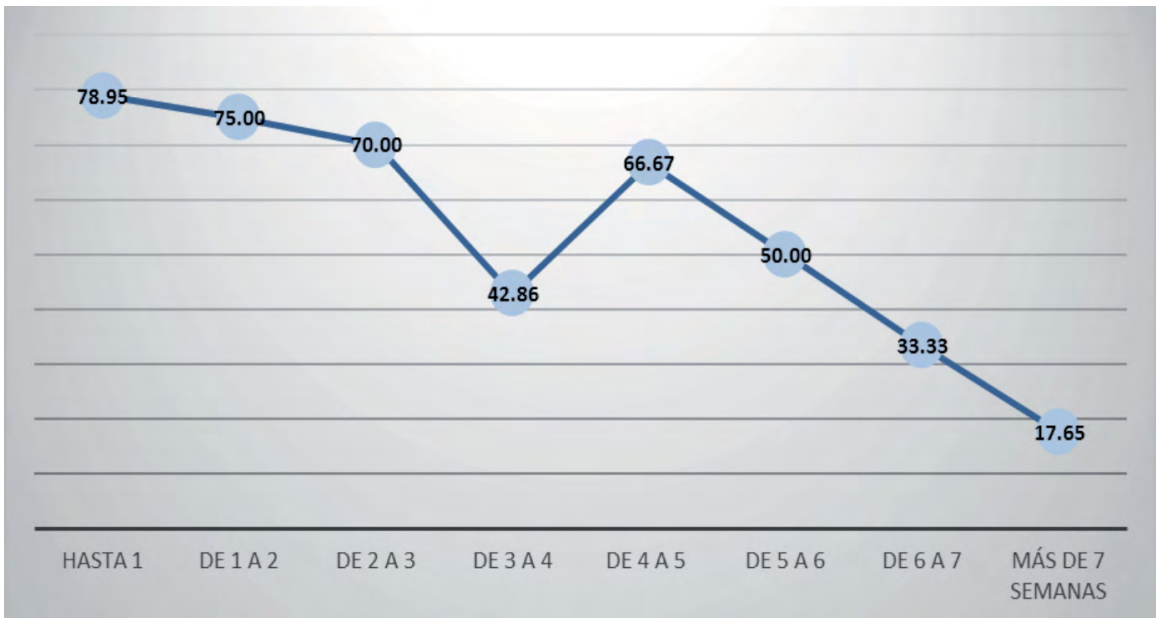

Fuente: Elaboración a partir de datos de la tabla 29.

De entre las distintas posibilidades de abandonar el CIE (tabla 30), la más frecuente es la ejecución de la expulsión (61\%), aunque caben otras posibilidades, como liberar a la persona por la imposibilidad de documentarla dentro de plazo (18\%), siendo el director del CIE el órgano autorizado para decretar discrecionalmente el cese del internamiento.

Tabla 30

\section{Modalidades de salida del CIE}

\begin{tabular}{lrc}
\hline \multicolumn{1}{c}{ Salida del CIE } & N. ${ }^{\circ}$ & $\%$ \\
\hline Salida para expulsión & 80 & 61,1 \\
Salida por imposibilidad de documentar & 24 & 18,3 \\
Salida por orden judicial & 18 & 13,7 \\
Salida por agotar plazo internamiento & 5 & 3,8 \\
Salida por traslado & 2 & 1,5 \\
Salida por orden administrativa & 2 & 1,5 \\
\hline Total & $\mathbf{1 3 1}$ & $\mathbf{1 0 0}$ \\
\hline
\end{tabular}

Fuente: Ministerio del Interior a través del Portal de Transparencia 
La Ley Orgánica de Extranjería señala que el juez competente para dejar sin efecto el internamiento es el juez de instrucción del lugar donde se practica la detención de la persona extranjera; esto es, el mismo que autorizó el citado internamiento (art. 62.6 LOEx.). El Reglamento sobre centros de internamiento de extranjeros, por su parte, se limita a indicar que el extranjero internado queda a disposición del juez o tribunal que autorizó u ordenó el internamiento (art. 2.2 RCIEs), de lo cual se ha de deducir que la puesta a disposición se refiere a una posible decisión sobre la salida del interno del centro. Pero junto con el juez, también cabe que sea el director del centro quien adopte el cese del ingreso, ya sea de oficio o a iniciativa de parte o del Ministerio Fiscal. En concreto, se indica que cuando hayan dejado de cumplirse las condiciones que llevaron al internamiento de la persona extranjera (riesgo de incomparecencia por carecer de domicilio o de documentación identificativa, actuaciones tendentes a dificultar o evitar la expulsión, existencia de condena o sanciones administrativas previas y de otros procesos penales o procedimientos administrativos sancionadores pendientes), ésta será puesta inmediatamente en libertad por la autoridad administrativa que la tenga a su cargo, es decir, el director del centro de internamiento (art. 37 1. ${ }^{\circ} \mathrm{RCIEs}$ ), poniéndolo en conocimiento del juez que autorizó la privación de libertad (art. 62.3 LOEx.). Por tanto, no se requiere que sea el juez de instrucción competente quien autorice la puesta en libertad de la persona internada.

En esta segunda modalidad no se precisa una nueva intervención judicial, aunque también cabe la posibilidad de que, en vía de recurso o atendiendo a otras circunstancias como la propia orden de expulsión, sea un juez $(13,7 \%)$, o la propia Administración (1,5\%), quien declare improcedente el internamiento. Cinco personas lograron su libertad tras agotar los 60 días legales.

Finalmente, respecto a la tasa de expulsión (tabla 31), debemos decir que en términos generales ronda el $61 \%, 20$ puntos por encima de la media del 41,4 \% del Estado (2.871 expulsados de 6.930 internados), aunque la tasa de Madrid (CIE de mayor internamiento desde el País Vasco) es 70,52 \% (1.036 expulsados de 1.469 internados). Esto nos indica que el perfil de las personas internadas procedentes del País Vasco responde a un perfil con menor tasa de expulsabilidad con respecto al CIE de Aluche, pero mucho mayor a la tasa global. 
Tabla 31

Tasa de Expulsión, País Vasco y Estado

\begin{tabular}{lcccc}
\hline \multirow{2}{*}{ Internados } & \multicolumn{2}{c}{ País Vasco (1) } & \multicolumn{2}{c}{ Estado (2) } \\
\cline { 2 - 5 } & $\mathrm{N} .{ }^{\circ}$ & $\%$ & $\mathrm{~N} .{ }^{\circ}$ & $\%$ \\
\hline No expulsados & 51 & 38,9 & 4.059 & 58,5 \\
Expulsados & 80 & 61,1 & 2.871 & 41.4 \\
\hline Total & 131 & $\mathbf{1 0 0 , 0}$ & $\mathbf{6 . 9 3 0}$ & $\mathbf{1 0 0 , 0}$ \\
\hline
\end{tabular}

Fuentes: (1) Ministerio del Interior a través del Portal de Transparencia; (2) Informe anual 2015 del Mecanismo Nacional de Prevención de la Tortura

\section{Conclusiones}

La extranjería en el País Vasco, y su incidencia en la Administración Pública y en la Justicia, es una materia necesitada de estudio permanente por sus particularidades competenciales y de localización geográfica. En algunos casos, como las expulsiones o internamientos, se trata de cifras relativamente bajas en relación con otros lugares del Estado, pero en otros ámbitos como las detenciones por infracción de la ley de extranjería o las readmisiones a través de la frontera con Francia, las cifras nos exigen una atención añadida a los procedimientos y mecanismos mediante las cuales éstas se producen. Vemos que hay una brecha entre el número de detenciones, el internamiento y el número de expulsiones. El centenar de expulsiones efectuadas en 2015 en el marco de la ley de extranjería contrastan con las 1.900 detenciones que se han producido en estas mismas fechas. Se trata, en definitiva, de un sistema cuyo propósito es la detención con meros fines sancionatorios más que la propia expulsión.

Una cuestión importante que invita a la reflexión es la relativa al perfil de las personas detenidas con orden de expulsión. En nuestro caso hemos podido observar que se trata, fundamentalmente, de un hombre magrebí, de entre 20-35 años, con una orden de expulsión dictada más o menos reciente (2014 o 2015) por estancia irregular (53.1a) o tal vez 57.2 LOEx. Tanto el género como la nacionalidad de los detenidos no se corresponde con la composición general de la población extranjera de referencia. La inmensa mayoría de los detenidos son hombres, cuando la proporción de hombres y mujeres extranjeras en el País Vasco es prácticamente la misma. Por otra parte, llama la atención que las principales nacionalidades de los detenidos no se corresponden con las de la 
población extranjera empadronada en el País Vasco. Marroquíes y argelinos están mucho más presentes entre los detenidos que entre la población general extranjera. Lo mismo ocurre con los originarios del África subsahariana. Hay una clarísima sobrerrepresentación de estos grupos de nacionalidad, mientras que latinoamericanos, asiáticos y europeos tienen mucha menos presencia entre los detenidos que entre la población general (especialmente los latinoamericanos). Cabe preguntarse por los motivos de estos desequilibrios. ¿Es la mayor "irregularidad" de estos grupos nacionales la que genera más detenciones? Suponiendo que así fuera, ¿es, realmente, tanta la diferencia? ¿No estarán interfiriendo en las detenciones algunos otros factores como la "visibilidad" y/o los estereotipos y prejuicios relativos a la "peligrosidad" de estos grupos de personas? Recordemos que nos estamos refiriendo en todo momento a detenciones por estancia irregular, no por la comisión de delitos.

En cuanto a la tramitación de los procedimientos sancionadores por permanencia irregular en territorio estatal, convendría reflexionar sobre la aplicación de los criterios a la hora de determinar si tramitarlos por la vía ordinaria o preferente. Tal y como se ha expuesto en líneas precedentes, la opción por una u otra forma es trascendental, ya que en el primer caso no es posible internar a la persona extranjera, mientras que en la segunda sí. Esto último no debe llevar a los operadores a optar sistemáticamente por esta segunda vía sin atender debidamente a las circunstancias concurrentes en cada caso.

En relación a las garantías jurídicas del proceso, cabe señalar que, pese a la intervención de un juez del ámbito penal, las garantías formales son limitadas, especialmente en lo que refiere a la posibilidad de defensa. Especialmente resulta escaso el tiempo para recabar información por parte del abogado para preparar en buenas condiciones los argumentos de defensa que eviten el internamiento. Asimismo, la duración de las vistas o comparecencias puede resultar relativamente corta, especialmente en lo que refiere a la práctica de determinados medios de prueba como la presencia de testigos o la petición de determinada documentación. En tanto que la resolución puede derivar en una privación de libertad de 60 días, sería interesante que se modulara el modo de comparecencia, tal vez mediante un sistema de citación, de cara a una mejor defensa jurídica.

Otro dato a tener en cuenta es la distancia a la que se ubican los CIEs de habitual internamiento desde el País Vasco. Esto no solo dificulta la relación de la persona internada con sus posibles allegados, sino también supone un impedimento para continuar con la defensa letrada en casos de recursos interpuestos contra el internamiento, o incluso con la causa principal de expulsión, si aún ésta no hubiera devenido firme. En todo caso, el artículo 61 LOEx prevé una serie de medidas cautelares diferentes 
al internamiento en un CIE: a) Presentación periódica ante las autoridades competentes; b) Residencia obligatoria en determinado lugar; c) Retirada del pasaporte; d) Cualquier otra medida cautelar que el juez estime adecuada y suficiente. Estas medidas también garantizarían en cierto modo la ejecutabilidad de la resolución de la expulsión. Sin embargo, tal vez sea el momento de explorar alternativas no solo al propio internamiento, sino al sistema sancionador de extranjería de manera integral (38). La expulsión, pese a la deriva comunitaria sobre la inevitabilidad del retorno de las personas en situación irregular, debería convertirse en una última ratio para casos de importante gravedad jurídica. Aún en estos casos, deberán hacerse valer los principios generales del Derecho Penal más garantista y progresista. Mientras tanto, la labor de la defensa letrada, la Fiscalía, el Poder Judicial y, por qué no, de la propia policía, está en el cumplimiento de los derechos fundamentales y de las garantías procesales de todas las personas, independientemente de su status jurídico-administrativo.

\section{Bibliografía}

ADAM MUÑOZ, María Dolores, «El internamiento preventivo del extranjero durante la tramitación del expediente de expulsión: (Comentario a la sentencia delTribunal Constitucional 144/1990 de 26 de septiembre)", en La Ley: Revista jurídica española de doctrina, jurisprudencia y bibliografía, núm. 3, 1991, págs. 970-978.

AIERBE, Peio; BARBERO, Iker; M. MAZKIARAN, Mikel, «De qué alternativas hablamos", en Mugak, núm. 64-65, 2013, págs. 29-30.

ANDRIJASEVIC, Rutvica. "From exception to excess: detention and deportations across the Mediterranean space.» Duke University Press, 2010.

BARBERO GONZÁLEZ, Iker; BLANCO FERNÁNDEZ DE VALDERRAMA, Cristina; ARRESE IRIONDO, Nieves; GONZÁLEZ MURUA, Ana Rosa, La defensa de los Derechos Fundamentales ante la detención, internamiento y expulsión de personas extranjeras. El caso de la Comunidad Autónoma Vasca, Tirant lo Blanch, Valencia, 2017.

CASTANEDO GARCÍA, María Esther, «Examen de la jurisprudencia existente relativa a los artículos 57 y 58 de la Ley orgánica 4/2000, de 11 de enero y su desarrollo reglamentario, y las sentencias de distintos tribunales superiores de justicia sobre la materian, en Revista de Derecho Migratorio y Extranjería, núm. 36, 2014, págs. 261-279.

(38) J.M: SÁNCHEZ TOMÁS "¿Hay alternativas al internamiento de inmigrantes irregulares?" $M u-$ gak, N. ${ }^{\circ}$ 64-65, págs. 31-34, 2013. P. AIERBE, I. BARBERO y M. MAZKIARAN, "De qué alternativas hablamos». Mugak, N. ‥ 64-65, 2013, págs. 29-30, 2013. 
Iker Barbero, Cristina Blanco y Nieves Arrese

FERNÁNDEZ OLALLA, Patricia, "Materias vinculadas a la extranjera que motivan la actuación del Ministerio Fiscal durante el servicio de guardia», en MARTÍNEZ ESCAMILLA, Margarita (coord.), Detención, internamiento y expulsión administrativa de personas extranjeras, Cuadernos Digitales de Formación del Consejo General del Poder Judicial, Madrid, 2015, págs. 235-246.

GIBNEY, Matthew J.; HANSEN, Randall, Deportation and the liberal state: the forcible return of asylum seekers and unlawful migrants in Canada, Germany and the United Kingdom, UNHCR, Geneva, 2003.

GONZÁLEZ BEILFUSS, Markus, "Los centros de internamiento de extranjeros. Régimen jurídico tras el Reglamento de 2014 y la STS de 20 de marzo de 2015». en Miguel Revenga Sánchez (coord.), José Joaquín Fernández Alles (coord.) Los centros de internamiento de extranjeros: régimen jurídico tras el Reglamento de 2014 y la STS de 10 de febrero de 2015. Valencia:Tirant lo Blanch

GONZÁLEZ BEILFUSS, Markus, "Detention for the purpouse of removal in Spain: Empirical and socio-legal approach to its functioning", en Materiali per una Storia della cultura giuridica, núm. 2, 2017, págs. 533-552.

JARRÍN MORÁN, Adriana; RODRÍGUEZ GARCÍA, Dan; DE LUCAS, Javier, "Los Centros de Internamiento para Extranjeros en España: una evaluación crítica», en Revista CIDOB d'afers internacionals, núm. 99, 2012, págs. 201-220.

LÓPEZ BENÍTEZ, Mariano, "El nuevo régimen jurídico de los Centros de Internamiento de Extranjeros», en Revista Vasca de Administración Pública, núm. 99-100, vol. II, 2014, págs. 1905-1935.

LORENZO JIMÉNEZ, José Vicente, "La expulsión de extranjeros por permanencia irregular en España: un análisis de la jurisprudencia delTribunal Supremo", en Revista de Derecho Migratorio y Extranjería, núm. 20, 2009, págs. 201-230.

MANZANEDO, Cristina, "Resoluciones de los juzgados de control de los centros de internamiento de extranjeros, CIE, 2009-2013», en Revista de Derecho Migratorio y Extranjería, núm. 34, 2013, págs. 249-259.

MARTÍNEZ ESCAMILLA, Margarita, «Expulsión e internamiento de extranjeros: ¿Quiénes están en los CIE?», en REIG FABADO, Isabel (coord.), Libertad de circulación, asilo y refugio en la Unión Europea, Tirant lo Blanch, Valencia, 2014, págs. 47-376.

MAZKIARAN, Mikel, "Recorrido por las leyes de extranjería en España», en Mugak, núm. 29, 2015, págs.

REQUEJO RODRÍGUEZ, Paloma, El internamiento de extranjeros, Tirant lo Blanch, Valencia, 2006.

RÍOS, Julián; SANTOS, Eduardo; ALMEIDA, Cristina, Manual para la defensa de Derechos Humanos de personas extranjeras encerradas en los Centros de Internamiento (CIE), Gakoa Liburuak, San Sebastián, 2014. 
SÁNCHEZTOMÁS José Miguel, «¿Hay alternativas al internamiento de inmigrantes irregulares?», en Mugak, núm. 64-65, 2013, págs. 31-34.

SÁNCHEZTOMÁS, José Miguel, «Detención, internamiento y expulsión de ciudadanos extranjeros en situación irregular: marco comunitario e internacional», en MARTÍNEZ ESCAMILLA, Margarita (coord.), Detención, internamiento y expulsión administrativa de personas extranjeras, Cuadernos Digitales de Formación del Consejo General del Poder Judicial, 2015, págs. 55-80.

SILVEIRA GORSKI, Héctor C., "Los Centros de Internamiento de Extranjeros y el futuro del Estado de Derecho", en Mientras tanto, núm. 83, 2002, págs. 93-102.

SOLANES CORELLA, Ángeles, "Un análisis crítico de los centros de internamiento de extranjeros en España: normativa, realidad y alternativas", en Revista Telemática de Filosofía del Derecho, núm. 19, 2016, págs. 60-61.

TOMÉ GARCÍA, José Antonio, Internamiento preventivo de extranjeros conforme al nuevo reglamento de los CIE, Marcial Pons, 2014.

VILLAVERDE MENÉNDEZ, Ignacio, «El régimen jurídico-constitucional de la detención e internamiento de los extranjeros con ocasión de su expulsión del Estado", en PRESNO LINERA, Miguel Ángel (coord.) Extranjería e inmigración: aspectos jurídicos y socioeconómicos, Tirant lo Blanch, 2004, págs. 147-197.

WELCH, Michael; SCHUSTER, Liza. "Detention of asylum seekers in the US, UK, France, Germany, and Italy: A critical view of the globalizing culture of control». Criminal Justice, 2005, vol. 5, núm. 4, págs. 331-355. 
LABURPENA: Euskal Autonomia Erkidegoan ez dago atzerritarrak barneratzeko zentrorik; beraz, autonomia-erkidego honetan atxilotzen dituzten eta barneratzeko agindua daukaten pertsonak Alucheko zentrora (Madril) edo, bestela, Zona Francako zentrora (Bartzelona) eramaten dituzte. Euskal Autonomia Erkidegoko instrukzioko epaitegietan 2015ean bideratu ziren 211 barneratze-espediente aztertzearen emaitza da lan hau. Espediente horiek eta aipatu ditugun zentroetako barneratze-datuak begiratu ahal izan ditugu, eta egoera irregularrean dauden atzerritarrak atxilotzeko, barneratzeko eta kanporatzeko prozesuen gaineko ikuspegi berritzailea lortu dugu. Hainbat aldagai gurutzatuta, prozesu horien auzi-jartzaile nagusiek ematen dituzten argudio nagusietara hurbildu gara; hala nola, hauetara: barneratzeko polizia-eskaerara, Fiskaltzaren, abokatuen eta atzerritarren beraien argudioetara, barneratzea onartzeko edo ukatzeko oinarri judizialetara edo, are, atzerritarrak barneratzeko zentroetatik askatzeko edo kanporatzeko inguruabarretara. Ikuspegi enpiriko hau, etorkizuneko ikerketetarako ez ezik, prozedura horren ohiko jardueran interesa duten abokatu, epai eta fiskalentzat ere erabilgarria izan daiteke.

GAKO HITZAK: Atzerritarrak barneratzeko zentroak. Espediente judizialak. Euskal Autonomia Erkidegoa.

RESUMEN: En el País Vasco no hay ubicado ningún Centro de Internamiento de Extranjeros, por lo que las personas detenidas en esta comunidad autónoma, y sobre las que pesa una orden de internamiento, son trasladadas a los centros de Aluche (Madrid) o, circunstancialmente, al de Zona Franca (Barcelona). El presente trabajo es el resultado del análisis de 211 expedientes de internamiento sustanciados en los juzgados de instrucción del País Vasco durante el 2015 a los que hemos tenido acceso directo, así como a los datos de internamiento de los propios centros mencionados, obteniendo una perspectiva novedosa hasta la fecha de los procesos de detención, internamiento y expulsión de la población extranjera en situación irregular. A través del cruce de distintas variables nos hemos aproximado a los principales argumentos esgrimidos por los actores principales de tales procesos, como la solicitud policial de internamiento, los argumentos de la Fiscalía, de la defensa letrada y del propio extranjero, los fundamentos judiciales para conceder o denegar el internamiento, o incluso las circunstancias en las que se producen las liberaciones o expulsiones desde los propios CIEs. Esta visión empírica puede ser no sólo de gran interés para futuras investigaciones, sino también de gran utilidad para operadores jurídicos como abogados, jueces o fiscales interesados en la práctica cotidiana de este procedimiento.

PALABRAS CLAVE: Centros de Internamiento para Extranjeros. Expedientes judiciales. País Vasco.

ABSTRACT: There is not Detention Centre for Foreigners located in the Basque Country, so detained persons in this Community with a confinement order are transferred to the Aluche Centre (Madrid) or incidentally to that of the Zona Franca (Barcelona). This work is the result of the survey over 211 confinement records before the courts of instruction in the Basque Country over 2015 that we have had 
direct access together with the confinement data provided by the aforementioned centres, obtaining an up until now innovative perspective of the process of arrest, confinement and expulsion of foreign population in irregular situation. Using the cross of several variables, we approach to the main arguments put forward by the relevant actors in those procedures, as the application for the confinement by the police, the reasons of the prosecutors, of the defence counsel and the foreigner $\mathrm{him} / \mathrm{h}$ erself, the judicial grounds to grant or reject placement, or even the circumstances where releases or expulsions take place from the same Detention centres. This empirical approach may be of interest not only for future studies but also of great use for practitioners as lawyers, judges or prosecutors interested in the day to day practice of this procedure.

KEYWORDS: Detention Centres for Foreigners. Judicial records. Basque Country. 